\title{
SECTIONAL MATRIX SYSTEM IN RECONSTRUCTION OF PROXIMAL CONTACT IN CLASS II RESIN RESTORATION
}

\author{
$\mathrm{N} \mathrm{Nahar}^{1 *}$, AKM Bashar ${ }^{2}, \mathrm{MA} \mathrm{Gafur}^{3}, \mathrm{D} \mathrm{H}$ Jeorge ${ }^{4}$
}

\section{AFFILIATION:}

1. Dr. Norun Nahar MS Resident (Phase-B)

Dept. of Conservative Dentistry \& Endodontics, Bangabandhu Sheikh Mujib Medical University (BSMMU)

2. Dr. A.K.M. Bashar

Associate Professor Dept. of Conservative Dentistry \& Endodontics, Bangabandhu Sheikh Mujib Medical University (BSMMU)

3. Md. Abdul Gafur Principle Scientific Officer Pilot Plant and Process Development Centre, Bangladesh Council of Scientific and Industrial Research (BCSIR)

4. Dr. Didarul Haque Jeorge Project Research Physician, ICDDRB

\section{Article info.}

Received: 03 July 2021

Accepted: 01 September 2021

Volume: Vol-11, Issue-2, October 2021

DOI: https://doi.org/10.3329/updcj.v11i2.56072

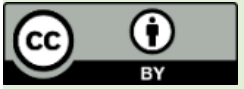

(C) Authors retain copyright and grant the journal right of first publication with the work simultaneously licensed under Creative Commons Attribution License CC - BY 4.0 that allows others to share the work with an acknowledgment of the work's authorship and initial publication in this journal.

https://creativecommons.org/licenses/by/4.0/

Publisher: Update Dental College, Dhaka, Bangladesh

Web: www.updatedentalcollege.edu.bd

E-mail: updcj@hotmail.com

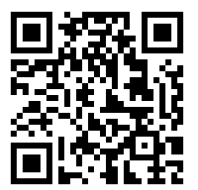

Scan QR code to see the latest issue

* Corresponding Author

\section{Dr. Norun Nahar}

MS Resident (Phase-B)

Dept. of Conservative Dentistry \& Endodontics, Bangabandhu Sheikh Mujib Medical University (BSMMU) Email: drnnahar01@gmail.com

Cell: 01675224618

\begin{abstract}
:
Background: Clinicians always faces some challenges to reconstruct proper proximal contact while restoring class-II cavity with composite resin due to its viscosity, elastic property and polymerization shrinkage. It has been claimed that use of sectional pre-contoured matrix band with separation ring will produce more reliable result for reconstruction of optimal proximal contact in class II composite resin restoration.

Purpose: To evaluate the efficacy of sectional pre-contoured matrix band with separation ring for reconstruction of optimal proximal contact in class II resin composite restoration. Methodology: One Nissin manikin model having the facility of placing and screwing all upper and lower sets of artificial human teeth and sixty-two (62) artificial human mandibular permanent $1^{\text {st }}$ molar teeth were collected. These 62 artificial human mandibular permanent $1^{\text {st }}$ molars were randomly assigned in two groups (A \& B) having 31 teeth in each. Standardized class II MO (mesio-occlusal) cavity were prepared on total 31 artificial $1^{\text {st }}$ molar in group $A$. The $2^{\text {nd }}$ premolar in the manikin model was replaced by metal cast duplicate and permanently fixed into the socket. All the Thirty-one (31) 1st molar teeth in group A, having Prepared class II cavity in each, were replaced one by another in the manikin distal to cast duplicated $2^{\text {nd }}$ premolar and restored with composite resin by using sectional pre-contoured matrix band with separation ring and another 31 uninstrumented intact artificial $1^{\text {st }}$ molars were include in group B as a reference group. After completion of restoration, newly developed proximal contact points were measured by using universal testing machine one after another. Same were also done in intact reference Group B. Measurement was done to assess the position of contact point, contact tightness and contact area of Group A and Group B on the same typodont. The results were analyzed statistically with post hoc Bonferroni test $(P<0.05)$. Result: Teeth restored with sectional precontoured matrix with separation ring (group A) provided the tighter contact and broadened area of contact where all the contact points were placed more occlusally compared to that of the intact un-instrumented reference teeth (group B).Statistically significant differences $(P<0.05)$ were produced in all the three parameters with each other. Conclusion: Teeth restored with sectional pre-contoured matrix band with separation ring failed to reconstruct the optimal proximal contact in class-II composite resin restoration in comparison to intact uninstrumented reference tooth.
\end{abstract}

KEYWORDS: Sectional matrix band, Proximal contact, Class II cavity, Resin restoration.

\section{INTRODUCTION}

Reconstruction of the intact interproximal surface particularly proper interproximal contact area is difficult by the clinician during restoration of class II cavity with composite resin due to its viscoelastic property ${ }^{1,2,3}$ and polymerization shrinkage ${ }^{4,5}$.

Two important factors are associated with establishment of the proximal surface these are proximal contact tightness and proximal contours. Different types of measures have already been taken for composite resin placement to maintain the anatomy of proximal contact area, special instrument such as variety of matrix systems, wedges and separation rings have been used to achieve the optimum proximal contour. The precontoured sectional matrix system is an excellent choice for class II composite restoration. Sectional pre-contoured matrix band with separation ring has been claimed to produce the superior proximal contour and tight proximal contact ${ }^{6,7}$. Proper reconstitution of this surface is largely depends on the shape of the matrix band and its accuracy of its placement. This 
matrix band is anatomically correct, properly contoured concave inner surface according to the tooth anatomy which allow restoration of interproximal anatomy. Sectional matrix band are designed not only with gingival contour but also with marginal ridge contour as well, which when placed at the appropriate height inter-proximally, it shapes the occlusal embrasure. This matrix has a hole tab extension which allow easy placement with pin tweezer and also has lateral holes to facilitate easy removal after restoration.

Some in vivo ${ }^{8,9,10}$ and in vitro ${ }^{11,12,13}$ study reported the effectiveness of this matrices to the reconstruction of contact tightness. Use of separation ring in combination of sectional matrix has been shown to achieve good contact tightness due to interdental separation of the ring applies during restoration and compensate the matrix thickness and material properties and the key factor for producing the tight proximal contact is obtaining the interdental separation during placement of restoration.

However commercial matrices are continuously developed for gaining the good proximal contact but no solid scientific evidence to support their claims. Therefore, the goal of the study was to assess the efficacy of pre-contoured sectional matrix band in combination with separation ring for reconstructing the optimal proximal contact in class II resin composite restoration.

\section{MATERIALS AND METHODS}

This in vitro study was carried out in the department of Conservative Dentistry and Endodontics, Bangabandhu Sheikh Mujib Medical University and Pilot Plant and Process Development Center, BCSIR. Considering all inclusion and exclusion criteria, sixty two (62) artificial mandibular right sided permanent $1^{\text {st }}$ molar teeth (\#46) and one Nissin manikin model (typodont) (Nissin, KYOTO, JAPAN) having the facility of placing and screwing all upper and lower sets of artificial human teeth were collected. A removable metallic cast guide (Fig-1A) was prepared to standardized preparation of the class II cavity. The right sided mandibular second premolar (\#45) within this typodont was replaced by metal cast ( $\mathrm{Co}-\mathrm{Cr}$ ) duplicate (Fig-1B) of the same; which was remain fixed into the corresponding socket of the typodont throughout the study. PREPARATION OF CLASS II CAVITY:

A standardized MO (mesio-occlusal) class II cavity by maintaining unique shape and dimension, was prepared in thirty one (31) of the right sided artificial mandibular $1^{\text {st }}$ molar teeth (\#46) from the collected sample by using diamond straight fissured burs (Mani, ISO 111/016, SF-13) in a highspeed hand piece (speed 180,000 rpm) with appropriate marking (on the individual bur by permanent marker according to the measurement ). The measurement of the proximal box of the prepared cavities were $1.5 \mathrm{~mm}$ mesio-distally, $4 \mathrm{~mm}$ occluso-gingivally and $4 \mathrm{~mm}$ bucco-lingually and the occlusall part of the prepared cavities were extended $2.5 \mathrm{~mm}$ mesio-

17| $P$ a g e distally, $2 \mathrm{~mm}$ occluso-pulpally and $2 \mathrm{~mm}$ bucco-lingually. After cavity preparation each of the thirty one (31) tooth was inserted and screwed into the corresponding socket of manikin model one after another in order to be filled with composite resin by using sectional pre-contoured matrix band with separation ring (palodont ${ }^{\circledR} \mathrm{V} 3$, Dentsply chaulk, USA), thus were included in group $A$; rest of the uninstrumented intact thirty one (31) artificial right sided mandibular $1^{\text {st }}$ molar (\#46) were considered as a control reference group $B$.

\section{MATRIX BAND PLACEMENT}

A pre-contoured sectional matrix band was selected and grasped with pin tweezer and placed to the space to be restored between the prepared class II cavity at the mesial surface of mandibular right sided $1^{\text {st }}$ molar and distal surface of the $2^{\text {nd }}$ premolar. Then gingival margin was closed by anatomic plastic wedge and separation ring was placed interproximally over the anatomic wedge (Fig-C)

\section{RESTORING (FILLING) THE PREPARED CAVITY:}

Packable type posterior composite resin restoration (G C Solar Sculpt, India) was used to fill the prepared cavity in lower right $1^{\text {st }}$ molar. The resin composite was inserted into the cavity in three increments. Each increment was cured from the occlusal side for 20 seconds with an LED light-curing unit (Coltolux LED, Coltene,USA). Finally after removal of the matrix and wedge, the restoration was receive additional 20 seconds curing both from the buccal and lingual sides of the proximal box.

After completion of restoration process in each of the thirty one (31) mandibular right sided $1^{\text {st }}$ molar teeth in group $A$ and in each thirty one (31) intact uninstrumented reference teeth in group B was placed into the manikin typodont one after another. Contact area in cast duplicated $2^{\text {nd }}$ premolar and restored $1^{\text {st }}$ molar were tested by using universal testing machine (Tinius Olsen, Hounsfield-H10ks, 500N sensor, UK) which was calibrated before use. A custom-made setup that was used allowed the forces were applied vertically on the interdental area of interest. A piece of $0.3 \mathrm{~mm}$ orthodontic wire was inserted under the contact area in a bucco-lingual direction. The wire was placed on a custom-made retainer intended to fit on the other end of the tension meter; it helped to hold down the wire at a horizontal direction throughout the movement. The wire was raised at a speed of $5 \mathrm{~mm} / \mathrm{min}$ in occlusal direction and the resistance force was enrolled during the movement (Fig-4). The maximum force $\left(F_{\max }\right)$ was enrolled, which was expressed the contact tightness (CT). The length of the contact arc (LCA), was calculated as the distance in the $X$ axis between the first force recording and the wire release position which represented the proximal contact area. Percentage (\%) ratio of the location of the maximum force $\left(F_{\max }\right)$ in the $\mathrm{X}$-axis and the LCA, which represent the location

Website: https://www.banglajol.info/index.php/UpDCJ 
of the contact point. The obtained data was recorded in predeveloped data sheet. The values were subjected to statistical analysis by post hoc Bonferroni test to define the difference between groups $(P<0.05)$.

RESULTS:

The sectional pre-contoured matrix system when used to restore the prepared class II cavities (group A) in the artificial simulated human mandibular molar teeth (typodont); presented statistically significant tighter contact (Table-I) than the intact un-instrumented reference teeth in the typodont.

In respect of the proximal contact area, A statistically significant broadened (Table-I) contact area were found than the intact uninstrumented reference teeth when precontoured sectional matrix system were used to reconstruct the prepared class II cavity but failed to produce the optimal contact area that is $(1.5-2 \mathrm{~mm})$.

While considering the position of the contact point, Teeth restored with sectional pre-contoured matrix band were placed more occlusally (Table-I) but the optimal contact were at the middle third of the crown as seen in the intact uninstrumented reference group.

Table I: Comparison of Contact tightness (CT), Length of contact arc (LCA) and \% ratio of the position of the maximum force between two groups.

\begin{tabular}{llcc}
\hline Variables & \multicolumn{2}{l}{ Values(Mean \pm SD)Range } & P value \\
& Group A $(\mathbf{n = 3 1 )}$ & Group B $(\mathbf{n = 3 1 )}$ & \\
\hline CT(N) & $26.04 \pm 9.53$ & $10.77 \pm 2.42$ & $<0.001^{*}$ \\
& $(5.70-53.30)$ & $(6.87-17.60)$ & \\
\hline LCA $(\mathbf{m m})$ & $3.08 \pm 1.18$ & $1.69 \pm 1.44$ & $<0.001^{*}$ \\
& $(0.586-5.30)$ & $(0.718-9.03)$ & \\
\hline PCP (\%) & $2.41 \pm 1.19$ & $1.11 \pm 0.46$ & $<0.001^{*}$ \\
& $(0.080-4.763)$ & $(0.432-2.656)$ & \\
\hline
\end{tabular}

Post hoc (Bonferroni test) were done to measure the level of significance between groups. Data were expressed as Mean \pm SD. $p$-value $\leq 0.05$ is considered statistically significant.

Table I shows sectional matrix system provided the significantly tighter proximal contact, broadened area of contact and contact point was placed more occlusally compared to that of the intact uninstrumented reference group. Position of contact point (PCP) is calculated from the percentage ratio of the position of maximum force and the LCA. Higher the PCP value than optimal indicate more occlusally the contact point is placed conversely lower the PCP value more cervically the contact point is placed.

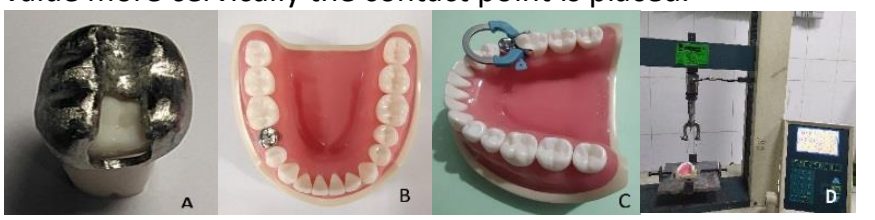

Figure 1: A) Metallic cast guide B) Metal cast of duplication mandibular $2^{\text {nd }}$ premolar C)Matrix band placed on the interproximal area between distal surface of mandibular $2^{\text {nd }}$ premolar and mesial surface of $1^{\text {st }}$ molar on the typodont D)Measurement procedure on Universal testing machine.

18| P a g e
DISCUSSION:

Proximal contact is the physiodynamic entity which is greatly influenced by tooth type, tooth location, postural change and restorative procedure ${ }^{18}$.A significant variation in contact tightness was seen both intra and inter individually and optimal value of contact tightness is still not established ${ }^{9,10,18}$. Abrams et al. ${ }^{19}$ found that tight contact hampers the passing dental floss where loose contact lead to food impaction, carious lesion. Whereas a six months clinical studies showed that changes of contact tightness after restoration will not remain stable overtime ${ }^{9}$

Loomans et al. ${ }^{16}$ concluded that proximal contact tightness in restored teeth should be comparable to the situation before treatment. Loomans et al. ${ }^{16}$ also showed in another study, tighter proximal contact give most satisfactory clinical result. So in this study when we compared proximal contact tightness produced by sectional matrix with intact uninstrumented reference teeth, sectional precontoured matrix band with separation ring presented the tighter proximal contact from the intact uninstrumented reference control teeth which previously confirmed by Kampouropoulos at el. ${ }^{14}$ who also observed the tightest contact than intact uninstrumented reference teeth \& other matrix system. Saber at el. ${ }^{15}$ found that sectional precontoured matrix band with separation ring provided the highest contact tightness than the other matrix system.

The use of separation ring with sectional matrix produce important significant factor for gaining the superior proximal contact tightness. Saber et al. ${ }^{15}$ showed that interdental separation is found to proportional to the proximal contact tightness. Along with the proximal contact tightness, reconstruction of the anatomically correct proximal contour is essential prerequisite for successful restoration. Contour is determined by combined value of contact area and position of contact point.

When we measured the proximal contact area, sectional precontoured matrix band with separation ring provided the significantly broadened contact area than the intact uninstrumented control group and fail to produce the optimal contact area. This finding was found by Kampouropoulos et al. ${ }^{14}$ where sectional matrix band produced broadened contact area than the other matrix system and intact uninstrumented teeth. Broadened contact area indicates the over contoured surface.

Whether tighter proximal contact and broadened contact area after restoration in class II cavity than the intact tooth is still now controversial though K. Phillips et al. ${ }^{17}$ concluded creating contact tightness and contact area similar to its natural adjacent and contralateral intact tooth is justified.

Considering the position of the contact point teeth restored with sectional matrix placed more occlusally than the intact uninstrumented teeth and fail to produce optimal position of

Website: https://www.banglajol.info/index.php/UpDCJ 
the contact point is in the middle third of the crown which was produced by the intact uninstrumented control teeth. Kampouropoulous et al. ${ }^{14}$ also observed that sectional matrix band fail to produce the optimal contact location like reference teeth.

\section{CONCLUSION:}

Sectional precontoured matrix band with separation ring failed to produce the acceptable proximal contact in class II composite resin restoration in comparison to intact uninstrumented reference tooth

\section{Citation:}

Norun Nahar, A.K.M. Bashar, Md. Abdul Gafur, \& Didarul Haque Jeorge. Sectional matrix system in reconstruction of proximal contact in class ii resin restoration. Update Dental College Journal, 11(2), 16-19. https://doi.org/10.3329/updcj.v11i2.56072

\section{REFERENCES:}

1. Lee IB, Son HH, Um CM. Rheologic properties of flowable, conventional hybrid, and condensable composite resins. Dent Mater. 2003 Jun;19(4):298-307.

https://doi.org/10.1016/S0109-5641(02)00058-1

2. Lee $\mathrm{IB}$, Cho $\mathrm{BH}$, Son $\mathrm{HH}$, Um CM. Rheological characterization of composites using a vertical oscillation rheometer. Dent Mater. 2007 Apr;23(4):425-32. https://doi.org/10.1016/j.dental.2006.02.013 PMid:16566997

3. Rüttermann S, Krüger S, Raab WH, Janda R. Polymerization shrinkage and hygroscopic expansion of contemporary posterior resin-based filling materials--a comparative study. J Dent. 2007 Oct;35(10):806-13. https://doi.org/10.1016/j.jdent.2007.07.014

PMid:17826883

4. Braga RR, Ballester RY, Ferracane JL. Factors involved in the development of polymerization shrinkage stress in resin-composites: a systematic review. Dent Mater. 2005 Oct;21(10):962-70 https://doi.org/10.1016/j.dental.2005.04.018 PMid:16085301

5. Demarco FF, Cenci MS, Lima FG, Donassollo TA, André Dde A, Leida FL. Class II composite restorations with metallic and translucent matrices: 2year follow-up findings. J Dent. 2007 Mar;35(3):231-7. https://doi.org/10.1016/j.jdent.2006.07.011 PMid:17034926

6. Loomans BA, Roeters FJ, Opdam NJ, Kuijs RH. The effect of proximal contour on marginal ridge fracture of Class II composite resin restorations. J Dent. 2008 Oct;36(10):828-32. https://doi.org/10.1016/j.jdent.2008.06.001 PMid:18621458

7. Peumans M, Van Meerbeek B, Asscherickx K, Simon S, Abe Y, Lambrechts $P$, Vanherle G. Do condensable composites help to achieve better proximal contacts? Dent Mater. 2001 Nov;17(6):533-41.

https://doi.org/10.1016/S0109-5641(01)00015-X PMID: 11567692.

8. Loomans BA, Opdam NJ, Bronkhorst EM, Roeters FJ, Dörfer CE. A clinical study on interdental separation techniques. Oper Dent. 2007 MayJun;32(3):207-11. https://doi.org/10.2341/06-73 PMid:17555170

19|P a g e
9. Loomans BA, Opdam NJ, Roeters FJ, Bronkhorst EM, Burgersdijk RC, Dörfer $\mathrm{CE}$. A randomized clinical trial on proximal contacts of posterior composites. J Dent. 2006 Apr;34(4):292-7. https://doi.org/10.1016/j.jdent.2005.07.008 PMid:16157438

10. Loomans BA, Opdam NJ, Roeters FJ, Bronkhorst EM, Burgersdijk RC, Dörfer CE. A randomized clinical trial on proximal contacts of posterior composites. J Dent. 2006 Apr;34(4):292-7. doi: 10.1016/j.jdent.2005.07.008. Epub 2005 Sep 12. PMID: 16157438. https://doi.org/10.1016/j.jdent.2005.07.008 PMid:16157438

11. Cenci MS, Lund RG, Pereira CL, de Carvalho RM, Demarco FF. In vivo and in vitro evaluation of Class II composite resin restorations with different matrix systems. The Journal of Adhesive Dentistry. 2006 Apr;8(2):127132.

12. Loomans BA, Opdam NJ, Roeters FJ, Bronkhorst EM, Plasschaert AJ. The long-term effect of a composite resin restoration on proximal contact tightness. J Dent. 2007 Feb;35(2):104-8 https://doi.org/10.1016/j.jdent.2006.05.004 PMid:16904254

13. Kampouropoulos D, Paximada C, Loukidis M, Kakaboura A. The influence of matrix type on the proximal contact in Class II resin composite restorations. Oper Dent. 2010 Jul-Aug;35(4):454-62. https://doi.org/10.2341/09-272-L PMid:20672731

14. Saber MH, Loomans BA, El Zohairy A, Dörfer CE, El-Badrawy W. Evaluation of proximal contact tightness of Class II resin composite restorations. Oper Dent. 2010 Jan-Feb;35(1):37-43 https://doi.org/10.2341/09-037L PMid:20166409

15. Loomans BA, Opdam NJ, Roeters FJ, Bronkhorst EM, Burgersdijk RC. Comparison of proximal contacts of Class II resin composite restorations in vitro. Oper Dent. 2006 Nov-Dec;31(6):688-93. https://doi.org/10.2341/05-133 PMid:17153978

16. Phillips K, Kois JC. Aesthetic peri-implant site development. The restorative connection. Dent Clin North Am. 1998 Jan;42(1):57-70. PMID: 9421670

17. Dörfer CE, von Bethlenfalvy ER, Staehle HJ, Pioch T. Factors influencing proximal dental contact strengths. Eur J Oral Sci. 2000 Oct;108(5):36877. $\quad$ https://doi.org/10.1034/j.1600-0722.2000.108005368.x PMid:11037752

18. Abrams H, Kopczyk R. Gingival Sequela from a Retained Piece of Dental Floss. The Journal of the American Dental Association. 1983;106(1):5758. https://doi.org/10.14219/jada.archive.1983.0030 PMid:6574168 